\title{
Maternal plasma vitamin D levels and associated determinants in late pregnancy in Harare, Zimbabwe: a cross-sectional study
}

Raylton P. Chikwati ${ }^{1 *}$, Cuthbert Musarurwa ${ }^{1}$, Kerina Duri ${ }^{2}$, Kudakwashe Mhandire ${ }^{1}$, Tracy Snyman ${ }^{3}$ and Jaya A. George ${ }^{3}$

\begin{abstract}
Background: The importance of vitamin D in bone health and calcium homeostasis has been well documented. However, emerging evidence supports the role of vitamin D beyond its recognised traditional roles. In pregnancy, vitamin D levels are crucial in sustaining both the maternal stores and optimal growth of the foetus. In Southern Africa, there is paucity of data on vitamin $D$ in pregnancy and related outcomes. To expand this body of knowledge, we assessed vitamin D levels in late pregnancy and (if any) associated maternal determinants in Harare, Zimbabwe.

Methods: Study participants comprised of 138 pregnant Zimbabwean women in their third trimester. These were stratified by HIV status; sampling median (IQR) gestation for HIV negative study participants was 34 weeks (26-41) and 31 weeks (20-40) in the HIV positive participants.

Maternal plasma 25 hydroxyvitamin $(\mathrm{OH})$ Dlevels were measured using the ClinPrepHigh Pressure Liquid Chromatography (HPLC) kit. Statistical analysis was carried out using the STATA statistical package version 13. A $p$-value of $<0.05$ was considered to be statistically significant.

Results: HIV infected participants had significantly higher mean $25(\mathrm{OH}) \mathrm{D}$ concentration $(112 \pm 33.4 \mathrm{nmol} / \mathrm{L})$ compared to the HIV uninfected $(100 \pm 27.1 \mathrm{nmol} / \mathrm{L}), p=0.032$.Participants whose samples were collected during summer had higher maternal $25(\mathrm{OH})$ D levels than those cART duration and maternal $25(\mathrm{OH}) \mathrm{D}$ levels $(p=0.031$, Spearman correlation $=0.28$ ).

Conclusions: Our findings show high mean levels of maternal $25(\mathrm{OH}) \mathrm{D}$ in late pregnancy in our setting and in the absence of vitamin D supplementation. Both HIV infection and season are significant determinants of maternal vitamin D levels. Summer season is associated with higher maternal plasma $25(\mathrm{OH}) \mathrm{D}$ levels. HIV infection is associated with increased maternal vitamin D levels. Prolonged use of CART, Tenolam E is associated with improved maternal 25(OH) D levels.
\end{abstract}

Keywords: Vitamin D, Pregnancy, Cohort, HIV status, Harare,Zimbabwe

\footnotetext{
* Correspondence: rayltonc@gmail.com

${ }^{1}$ Department of Chemical Pathology, University of Zimbabwe, College of

Health Sciences, P.O. Box A178, Avondale, Harare, Zimbabwe

Full list of author information is available at the end of the article
}

(c) The Author(s). 2019 Open Access This article is distributed under the terms of the Creative Commons Attribution 4.0 International License (http://creativecommons.org/licenses/by/4.0/), which permits unrestricted use, distribution, and reproduction in any medium, provided you give appropriate credit to the original author(s) and the source, provide a link to the Creative Commons license, and indicate if changes were made. The Creative Commons Public Domain Dedication waiver (http://creativecommons.org/publicdomain/zero/1.0/) applies to the data made available in this article, unless otherwise stated. 


\section{Background}

The traditional roles of vitamin D $[25(\mathrm{OH}) \mathrm{D}]$ in calcium and phosphorous metabolism have been well characterised. Growing evidence supports the non-traditional roles of $25(\mathrm{OH}) \mathrm{D}$ in various conditions and diseases that include infectious diseases [1-4], autoimmune diseases [5],cardiovascular diseases [6, 7], metabolic disorders [8], cancer [9] and all-cause mortality [4].

Globally, there is growing literature on suboptimal vitamin D levels $(<80 \mathrm{nmol} / \mathrm{L})$ and associations with disease outcomes in different populations. The highest prevalence of suboptimal vitamin $\mathrm{D}$ levels has been reported in pregnancy [3, 10-12] and lactation [13], exclusively breastfed infants [14], human immunodeficiency virus (HIV) infected individuals [15-18] and dark skinned individuals $[19,20]$. In a recent meta-analysis, Saraf and colleaguesreported that globally, $54 \%$ of pregnant women had suboptimal vitamin D levels, qualifying vitamin D status as an emerging public health problem [21].

In pregnancy, the adequate provision of vitamin $\mathrm{D}$ is necessary for sustainable maternal stores and for optimal foetal development [22]. Gestational concentrations of active vitamin D 1,25(OH)2D increase by $50-100 \%$ over the non-pregnant state [23]. This is due to an uncoupling mechanism on the physiological Parathyroid Hormone (PTH) role of activating vitamin D during pregnancy. As such, it is thought that the active vitamin D metabolite, $25(\mathrm{OH}) \mathrm{D}$ levels decrease to compensate this physiological change.

Many groups have reported that vitamin D deficiency is widespread among HIV-infected.

persons, with prevalence estimates ranging from 29 to 89\% in European and US HIV-infected populations [17]. Only two studies within Sub-Saharan Africa have documented hypovitaminosis D in HIV positive women. One study reported $31.8 \%$ vitamin D insufficiency [25 $(\mathrm{OH})$ $\mathrm{D}<80 \mathrm{nmol} / \mathrm{L}$ ] among Batswana HIV positive women at delivery who were receiving Highly Active Antiretroviral Therapy (HAART) [3]. The other study reported 39\% vitamin D insufficiency among HAART naïve Tanzanian women between 12 and 27 weeks of pregnancy [4].

Furthermore, fewer studies have been also been done on healthy pregnancy women in Africa. One study was amongst Tanzanians reporting $1 \%$ vitamin deficiency $(<50 \mathrm{nmol} / \mathrm{L})$ and $2 \%$ insufficiency $(<75 \mathrm{nmol} / \mathrm{L})$ [24]. In a Kenyan population, Toko et al. reported that at 26 weeks gestation, the women had 51 and $21 \%$, vitamin $\mathrm{D}$ insufficiency and deficiency respectively [25]. The wide discordance of these results therefore warrants further comparative studies.

To the best of our knowledge only four studies have reported serum vitamin D status on Zimbabweans. However none of these have focused on pregnancy and pregnancy related outcomes. Furthermore there is paucity of data on vitamin D status in HIV-infected populations from low income settings. We carried out a cross sectional study that estimated vitamin $\mathrm{D}$ status of pregnant women and assessed maternal determinants of serum vitamin D status.

\section{Methods}

\section{Study setting and design}

In this comparative cross sectional study, we assayed plasma $25(\mathrm{OH}) \mathrm{D}$ concentrations on archived maternal plasma samples originating from an ongoing prospective cohort study, The University of Zimbabwe Birth Cohort Study (UZBCS), which began recruitment in February 2016. Briefly, the main cohort study randomly enrolled consenting pregnant women from four primary healthcare clinics in high density suburbs of Harare, Zimbabwe. At enrolment, the study participants completed a structured questionnaire and provided blood samples. From these we identified 210 participants enrolled into the main study within the period February 2016 and August 2016. From these, 69 HIV positive and 69 HIV negative participants were randomly selected for the present study.

\section{Participants}

Study participants consisted of randomly sampled consenting pregnant women aged 18-49 years who planned to stay in Harare for at least 1 year post delivery. Systematic sampling was used to recruit participants from a sampling frame of 210 participants (105 HIV negative, 105 HIV positive) enrolled from February 2016 to August 2016. The sampling was done by arranging the study participants according to a date based sequence from sample collection. The selection was done by removing two participants after every 10.

We excluded pregnant women with self-reported kidney disease, liver disease, gut or malabsorption disorders, and granulomatous disease and on vitamin $\mathrm{D}$ and/or calcium supplements. Data on socio-demographics, general maternal health, maternal medical history and anthropometric measurements was abstracted from the cohort records. We also obtained data on potential determinants of vitamin D status.

The sample size was calculated to ensure a statistical power of $80 \%$ and a probability of less than 0.05 for detecting significant differences between maternal $25(\mathrm{OH})$ $\mathrm{D}$ levels and associated covariates. For the calculations, a vitamin D insufficiency prevalence of $31.8 \%$ was obtained from a study in Batswana HIV positive women at delivery (3) and $11 \%$ vitamin D insufficiency in healthy pregnant women from the NHANES study [26]. The following formula was used for calculating the adequate sample size; $n=Z^{2} P(1-P) / d^{2}$ Where $n$ is the sample size, $\mathrm{Z}$ is the statistic corresponding to level of confidence, $\mathrm{P}$ is expected prevalence and $\mathrm{d}$ is precision 
(corresponding to effect size). From a minimum calculated sample size of 124 participants, we recruited 137 after adding a $10 \%$ attrition factor to anticipated difficulties in assays, from which 10 were excluded from the final analysis due to technical problems during the HPLC assays. These consisted of 5 HIV negative and 5 HIV positive women.

\section{Laboratory methods}

Plasma 25(OH) D concentrations were measured at the National Health Laboratory Services laboratory in Johannesburg, South Africa. Plasma 25(OH) D was quantified using the ClinRepHigh Pressure Liquid Chromatography (HPLC) kit (Recipe, Munchen, Germany). This method is able to resolve $25(\mathrm{OH}) \mathrm{D} 2$ from $25(\mathrm{OH}) \mathrm{D} 3$ using a photodiode array detector (PDA). The analytical column used for the present study consisted of octadecylsilane molecules $(\mathrm{C} 18)$ bonded to silica particles as the stationary phase. The mobile phase used was highly polar consisting of a dilute organic solvent. A test solution was run at least twice to monitor the adequacy of the retention time and resolution of the peaks and that the baseline had stabilised. The working standard curve was used to calculate the unknown 25(OH) D2/D3 in the study samples. The standards and internal controls were prepared from commercially lyophilised pooled serum samples traceable to the National Institute of Standards and Technology Standard Reference Material 972, [25 $(\mathrm{OH})$ D NIST standards. Manual integration was done on the chromatograms to better peak resolution. Quality control was also monitored to ensure conformance of each test run.

The intra-assay variation of the method ranged from $0.9-4.9 \%$ and the inter-assay variation ranged from 3.0 $4.9 \%$. The laboratory participates in a vitamin D external quality assurance scheme (DEQAS). The limit of detection for $25(\mathrm{OH}) \mathrm{D} 3$ and $25(\mathrm{OH}) \mathrm{D} 2$ was $2.5 \mathrm{nmol} / \mathrm{L}$ and 7.5 $\mathrm{nmol} / \mathrm{L}$ respectively. Any 25(OH)D2 below the limit of detection was assigned a value of zero. Definitions on vitamin D status was as follows: sufficiency $(80-100 \mathrm{nmol} / \mathrm{L})$, insufficiency $(<80 \mathrm{nmol} / \mathrm{L})$ and deficiency $<50 \mathrm{nmol} / \mathrm{L}[27,28]$.

\section{Statistical analysis}

Statistical analysis was carried out using the STATA statistical software package version 13 (StataCorp LP, College Station, TX, USA). The data is presented as median (IQR) if non- parametric or mean $( \pm \mathrm{SD})$ for parametric data. The Mann-Whitney and Kruskal-Wallis were used for non-parametric comparisons. Chi square tests were used to compare categorical variables. Continuous variables were compared by the Spearman's Correlation. Multivariate linear regression analysis was performed to determine the association between covariates and $25(\mathrm{OH}) \mathrm{D}$ levels. We used a stepwise regression approach through which all candidate variables to $25(\mathrm{OH}) \mathrm{D}$ levels in the model were checked to see if their significance was reduced below the tolerance level of 0.1 (Table 3). All nonsignificant variables $(p>0.1)$ found in the model were removed.

\section{Results \\ Study population}

A total of 137 participants of whom 69 were HIV infected was randomly selected forenrolment. $25(\mathrm{OH}) \mathrm{D}$ concentrations were available for 127 (92\%) participants. The clinico-demographic characteristics of these are presented in Table 1.

The HIV infected participants were significantly older than the HIV- uninfected $(p<0.001)$

On the other hand, the HIV uninfected had significantly more advanced pregnancy with a median (IQR) of 34(26-41) weeks $(p<0.001)$. There were no significant differences in weight, blood pressure, monthly income and season of sampling between the two groups (Table 1).

\section{Maternal plasma $25(\mathrm{OH}) \mathrm{D}$ concentrations}

The overall mean for maternal plasma $25(\mathrm{OH}) \mathrm{D}$ concentration was $106 \mathrm{nmol} / \mathrm{L}( \pm 30.9)$ with $103(79.5 \%)$ participants classified as vitamin D sufficient $(\geq 80$ $\mathrm{nmol} / \mathrm{L}), 24(18.9 \%)$ as insufficient $(50.0-79.9 \mathrm{nmol} / \mathrm{L})$ and $2(1.6 \%)$ as deficient $(<50 \mathrm{nmol} / \mathrm{L})$.

There was a significant difference in mean plasma 25 $(\mathrm{OH}) \mathrm{D}$ between HIV negative participants, $100 \mathrm{nmol} / \mathrm{L}$ $( \pm 27.1)$ and HIV positive participants, $112 \mathrm{nmol} / \mathrm{L}( \pm 33.4)$ $(p=0.032)$ (Fig. 1). Although mean plasma vitamin D concentration was significantly higher in the HIV infected

Table 1 Participant Clinico-demographics

\begin{tabular}{|c|c|c|c|}
\hline Characteristic & HIV negative $n=63$ & HIV positive $n=64$ & $p$-Value \\
\hline Age, y (mean, SD) & $26.6(5.8)$ & $30.3(6.2)$ & $<0.001$ \\
\hline Weight, kg (median, IQR) & $68(51-109)$ & $68.5(48-109)$ & 0.725 \\
\hline $\begin{array}{l}\text { Gestational age, wk. } \\
\text { (median, IQR) }\end{array}$ & $34(26-41)$ & $31(20-40)$ & $<0.001$ \\
\hline \multicolumn{4}{|l|}{ Blood Pressure, mmHg } \\
\hline Systolic, median (IQR) & $108(87-153)$ & $110(93-138)$ & 0.282 \\
\hline Diastolic, median (IQR) & $67(28-97)$ & $69(28-92)$ & 0.727 \\
\hline Monthly income, USD & $268(40-1000)$ & $240(0-850)$ & 0.777 \\
\hline \multicolumn{4}{|l|}{ Marital Status, n (\%) } \\
\hline Married & $58(92.1 \%)$ & $43(67.2 \%)$ & $<0.001$ \\
\hline Single & $0(0.0 \%)$ & $3(4.7 \%)$ & 0.010 \\
\hline Cohabitating & $5(7.9 \%)$ & $16(25.0 \%)$ & \\
\hline Divorced/Separated & $0(0.0 \%)$ & $2(3.1 \%)$ & \\
\hline \multicolumn{4}{|l|}{ Season of Sampling $n,(\%)$} \\
\hline Summer (Dec-Feb) & $9(14.3 \%)$ & $8(12.5 \%)$ & 0.766 \\
\hline Autumn (Mar-May) & $38(60.3 \%)$ & $38(59.4 \%)$ & 0.918 \\
\hline Winter (June-Aug) & $16(5.4 \%)$ & $18(28.1 \%)$ & 0.731 \\
\hline
\end{tabular}




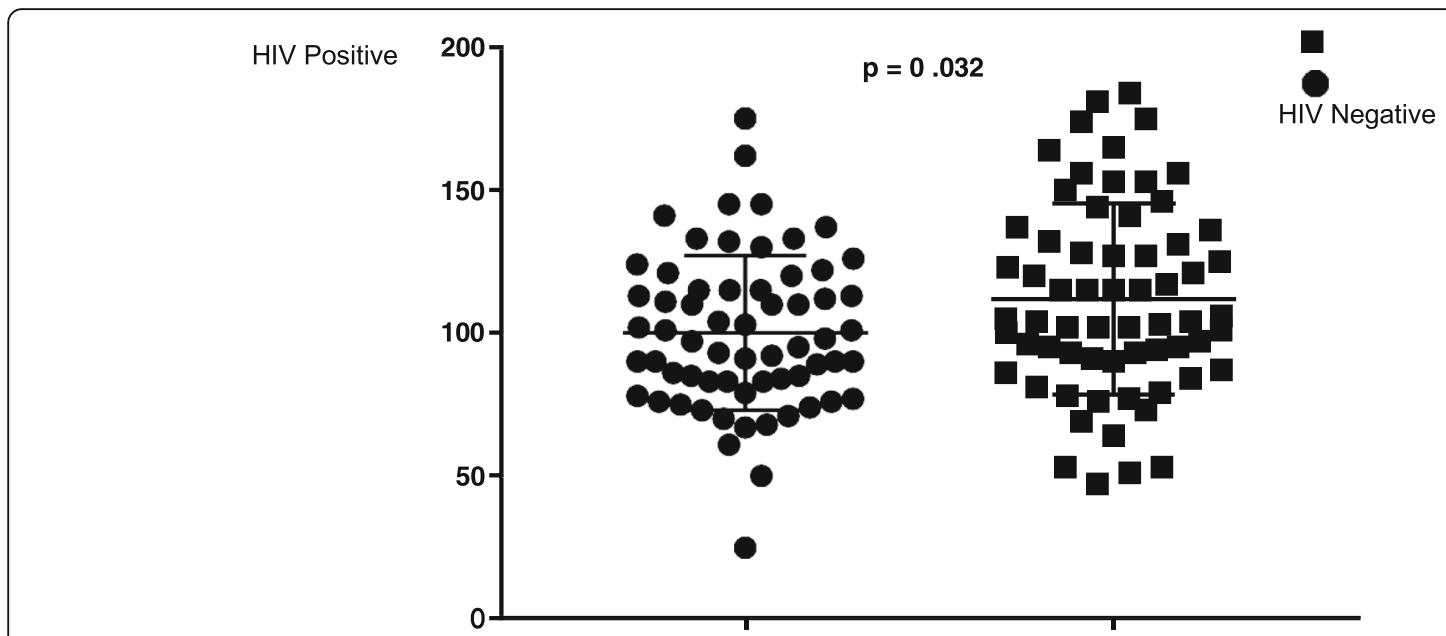

Fig. 1 Maternal $25(\mathrm{OH})$ D concentrations by HIV status

women, there were no significant differences in the proportions of participants in each of the three pre-defined strata of vitamin D status (Table 2).

\section{Maternal plasma $25(\mathrm{OH}) \mathrm{D}$ concentrations by season of sampling}

Participants were enrolled over summer, autumn and winter. We compared mean plasma vitamin D concentrations by season of enrolment (Fig. 2). Overall mean plasma $25(\mathrm{OH})$ D concentrations were significantly different by season of sampling with highest mean concentrations observed in summer. The trend was unchanged when participants were stratified by HIV status.

\section{Maternal $25(\mathrm{OH}) \mathrm{D}$ and combination antiretroviral therapy (cART) duration}

The correlation between plasma maternal 25(OH) D and duration on cART was determined (Fig. 3). There was a weak positive correlation $(\mathrm{r}=0.28)$ between maternal plasma $25(\mathrm{OH}) \mathrm{D}$ concentrations and duration on cART.

\section{Determinants of maternal $25(\mathrm{OH}) \mathrm{D}$ concentrations}

HIV status and season of sampling had significant influence on maternal $25(\mathrm{OH}) \mathrm{D}$ concentrations (Table 3). Maternal $25(\mathrm{OH}) \mathrm{D}$ increased by $12.8 \mathrm{nmol} / \mathrm{L}$ when the

Table 2 Sub-categories of maternal $25(\mathrm{OH})$ D concentrations $[27,28]$

\begin{tabular}{llll} 
& $\begin{array}{l}\text { HIV Negative } \\
n=63\end{array}$ & $\begin{array}{l}\text { HIV Positive } \\
n=64\end{array}$ & $P$ value \\
\hline $\begin{array}{l}\text { Vitamin D status, }(n, \%) \\
\text { Sufficient: }\end{array}$ & $48(76.2 \%)$ & $53(82.8 \%)$ & 0.571 \\
$\begin{array}{l}25(\mathrm{OH}) \mathrm{D} \geq 80 \mathrm{nmol} / \\
\text { LInsufficient: }\end{array}$ & $14(22.2 \%)$ & $10(15.6 \%)$ & 0.564 \\
$\begin{array}{l}25(\mathrm{OH}) \mathrm{D} 50.0-79.9 \mathrm{nmol} / \\
\text { LDeficient:25(OH) D }<50 \mathrm{nmol} / \mathrm{L}\end{array}$ & $1(1.6 \%)$ & $1(1.6 \%)$ & 0.943 \\
\hline
\end{tabular}

HIV status changes from negative to positive. In addition the transition from summer to winter was associated with a $42.5 \mathrm{nmol} / \mathrm{L}$ decrease in $25(\mathrm{OH}) \mathrm{D}(p<0.001)$ (Table 3).

\section{Discussion}

\section{Maternal $25(\mathrm{OH}) \mathrm{D}$ concentrations}

To our knowledge, this is the first study to investigate 25 $(\mathrm{OH}) \mathrm{D}$ concentrations, determinants of $25(\mathrm{OH}) \mathrm{D}$ in late pregnancy on Zimbabwean women. The prevalence of 25 $(\mathrm{OH}) \mathrm{D}$ deficiency, insufficiency and sufficiency in our study was $1.6,11.0$ and $87.4 \%$ respectively. This was an unexpected finding in that most literature cites a widespread global vitamin $\mathrm{D}$ deficiency in pregnant women ranging from 10 to $90 \%$ in non-African and $21-37 \%$ in African populations [25, 29-33]. Such differences could indicate that our population has higher vitamin D levels incomparison to current literature. Another possibility is that the cutoff values used in defining vitamin D deficiency in previous literature were inappropriate for pregnant women [27, 28].

Our results are however in concordance with findings on pregnant Tanzanian women which reported $1 \%$ vitamin D deficiency, 2\% insufficiency and an overall mean of $138.5( \pm 35.0) \mathrm{nmol} / \mathrm{L}$ [24]. In the current study, mean 25 $(\mathrm{OH}) \mathrm{D}$ was $106 \mathrm{nmol} / \mathrm{L}( \pm 30.9)$. As expected the mean plasma vitamin $\mathrm{D}$ concentration was higher in these pregnant participants than the $75-84.7 \mathrm{nmol} / \mathrm{L}$ reported on non-pregnant African populations $[1,3,4,10]$.

The apparent differences between $25(\mathrm{OH}) \mathrm{D}$ concentrations in the pregnant versus the non-pregnant could be explained by the physiology of vitamin $\mathrm{D}$ metabolism. During pregnancy, the concentration of vitamin D-binding protein (DBP) increases in response to elevations in oestrogen $[24,29]$. The higher binding capacity of plasma $25(\mathrm{OH}) \mathrm{D}$ and expansion of blood volume in pregnancy translates to an increased $25(\mathrm{OH}) \mathrm{D}$ pool size. In the third 

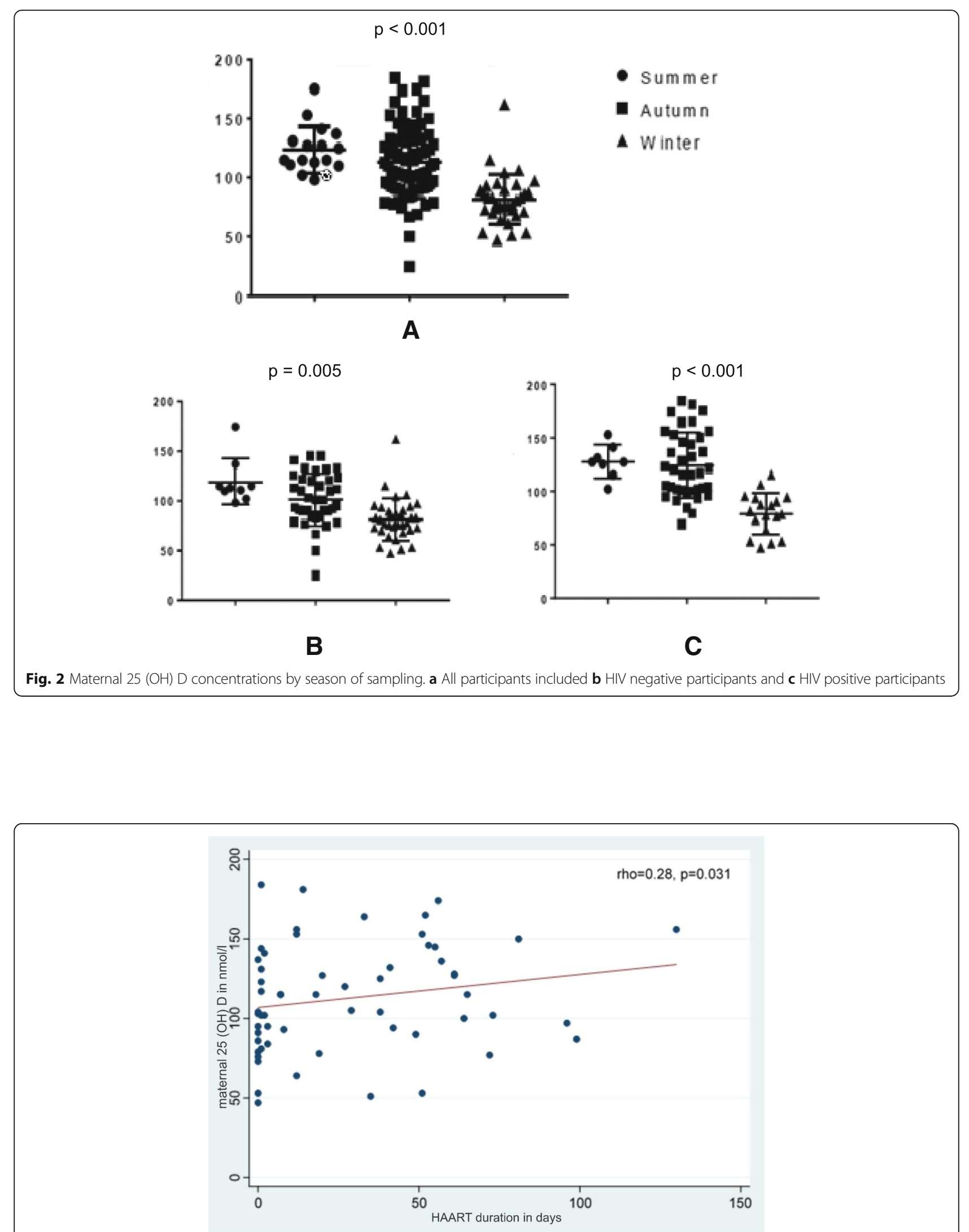

Fig. 3 CART duration and maternal $25(\mathrm{OH}) \mathrm{D}$ concentrations 
Table 3 Step-wise Regression of Predictible Variables

\begin{tabular}{llll}
\hline Variable & Coeffient. & Standard error & $P$-value \\
\hline HIV status & 12.20341 & 4.950488 & 0.015 \\
Age & 0.4354106 & 0.3737257 & 0.246 \\
Gestational age & 0.1715963 & 0.5217306 & 0.743 \\
Season & & & \\
$\quad$ Autumn & -8.672066 & 6.71355 & 0.199 \\
$\quad$ Winter & -44.99294 & 7.469283 & $<0.001$ \\
Removing variables with $p>0.1$ & & \\
$\quad$ HIV Status & 12.80705 & 4.696735 & 0.007 \\
$\quad$ Winter season & -42.48865 & 7.860597 & $<0.001$ \\
\hline
\end{tabular}

trimester, there is also reduced insulin sensitivity which enhances sequestration of vitamin $\mathrm{D}$ from the adipose tissue thereby increasing the circulating pool of $25(\mathrm{OH}) \mathrm{D}$ [34]. Furthermore, there is a pregnancy associated decoupling mechanism on the delaying the deactivation of $25(\mathrm{OH}) \mathrm{D}$ by the enzyme placental 24-hydroxylase (CYP24A1) thereby increasing the half-life of $25(\mathrm{OH}) \mathrm{D}$ [35].

On the other hand there is a compelling need to establish specific reference ranges for pregnant women. Currently the Institute of Medicine and the Endocrine Society guidelines does not have $25(\mathrm{OH})$ D reference ranges in pregnant women [36].

\section{Determinants of maternal $25(\mathrm{OH}) \mathrm{D}$ Maternal $25(\mathrm{OH}) \mathrm{D}$ and HIV status}

Our finding of significantly higher maternal $25(\mathrm{OH})$ D concentrations in HIV-infected women is in discordance with findings from a number of studies that have reported an association between HIV infection and lower mean plasma values of maternal $25(\mathrm{OH}) \mathrm{D}[1,3,4]$. We speculate this difference could have been due to the effect of cART. However, the effects of cART on vitamin D are regimen dependent. Some drugs are associated with lower levels and some with higher levels. Although not assessed in this study, prolonged exposure to sunlight and improved well-being could also have contributed to the higher maternal $25(\mathrm{OH})$ D levels.

Although information on CD4 wasn't included in this analysis, we speculate that with prolonged use of cART, the immune status of those individuals had improved. In support, Ramayo et al reported that vitamin D deficiency was more prevalent among cART-naive patients as compared to those receiving cART $(p=0.04)$ [18]. According to Haug et al., prolonged use of cART is associated with improved $25(\mathrm{OH})$ D concentrations along with immunological and clinical parameters of disease progression such as CD4 and tumor necrosis factor (TNF)- $\alpha$ [36]. HIV induced chronic inflammation characterised by TNF- $\alpha$ overproduction, may result in renal $1 \alpha$-hydroxylase impairment [18] leading to reduced parathyroid stimulatory effect on 1 ,
$25(\mathrm{OH}) 2 \mathrm{D}$ production thereby leading to the accumulation of the substrate $25(\mathrm{OH}) \mathrm{D}$ in circulation.

On stratifying study participants by HIV status, a significant association was observed between cART duration and maternal $25(\mathrm{OH})$ D concentrations $(p=0.031$, Spearman correlation $=0.28$ ) (Fig. 3-3).

We observed significant correlation between duration on cART and maternal plasma $25(\mathrm{OH}) \mathrm{D}$ concentrations, a finding that is conflicted with reports in Caucasian populations that reported that cART therapy particularly NNRTIs as risk factors that further decreased $25(\mathrm{OH}) \mathrm{D}$ levels $[18,37]$. This was not the case in our population, which could be attributed to racial differences, possibly genetic polymorphisms in the metabolism of vitamin D.

\section{Maternal $25(\mathrm{OH}) \mathrm{D}$ and $\mathrm{CART}$}

At the time of enrolment, the HIV-infected study participants were on a cART regimen of Tenolam E (Tenofovir/Efavirenz/Lamivudine). Tenofovir and Efavirenz have been reported as having direct effects on enzymes involved in vitamin $\mathrm{D}$ metabolism, with the majority of studies reporting an association of these drugs with 25 $(\mathrm{OH}) \mathrm{D}$ deficiency $[38,39]$. The combined effect of these drugs has not been investigated in literature therefore making it difficult to decipher the association with the unexpected elevation in $25(\mathrm{OH}) \mathrm{D}$. Individually, efavirenz has been shown to induce cytochrome P450 CYP24, which is responsible for adding a hydroxyl group on both $25(\mathrm{OH}) \mathrm{D}$ and $1,25(\mathrm{OH}) 2$ converting both to their inactive metabolites [40]. Efavirenz also reduces the expression of the cytochrome CYP2R1, which is responsible for vitamin D activation [41]. Tenofovir exerts its effect by inducing tubular dysfunction thereby compromising the function of the kidney enzyme 1a-hydroxylase which converts $25(\mathrm{OH}) \mathrm{D}$ to $1,25(\mathrm{OH}) \mathrm{D}$ [42]. These individual effects would thus have lowered the maternal serum $25(\mathrm{OH})$ D concentrations in our population, which was not the case.

\section{Maternal $25(\mathrm{OH}) \mathrm{D}$ and season of sampling}

As expected, summer was associated with the highest maternal plasma $25(\mathrm{OH}) \mathrm{D}$ concentrations. This is in agreement with a number of published studies that have reported positive associations between seasonal changes and vitamin D status [43-45]. This effect is due to the seasonal variations in solar radiation, with the highest intensity occurring in summer resulting in maximal dermal synthesis of vitamin D. In addition, low temperatures and low relative humidity during winter are significant risk factors contributing factors to these variations in $25(\mathrm{OH}) \mathrm{D}$ concentrations [45].

\section{Strengths and limitations}

The strengths of this study include random sampling from four peri-urban study sites and sampling at different seasons 
to eliminate confounding effect of season on vitamin D synthesis. In addition, the HPLC method used for analysis of samples was traceable to the LC-MS reference method, participated in an external quality assurance scheme by DEQAS and the internal quality exhibited good precision and accuracy with the controls used.

\section{Conclusions}

We present baseline data on vitamin D status in pregnant women in a black African population. In our setting, we documented high maternal vitamin D levels deficiency in the absence of vitamin D supplementation. HIV infection and season were significant covariates affecting the maternal vitamin D concentrations.

\begin{abstract}
Abbreviations
1,25(OH)2D: 1a, 25 -hydroxyvitamin D; $25(\mathrm{OH}) \mathrm{D}: 25$ hydroxyvitamin D; CART: Combination Active Antiretroviral Therapy; CYP27A1: Cytochrome P450 27A1; CYP27B1: Cytochrome P450 27B1; CYP2R1: Cytochrome P450 2R1; DEQAS: Vitamin D External Quality Assessment Scheme; HIV: Human Immunodeficiency Virus; IFCC: International Federation of Clinical Chemistry; NIST: National Institute of Standards and Technology SRM: Standard reference material; nmol/L: nano-moles per liter; NNRTIs: Non-Nucleoside Reverse Transcriptase Inhibitors; PTH: Parathyroid Hormome; UZBCS: University of Zimbabwe Birth Cohort Study; VBP: Vitamin D binding protein; VDR: Vitamin D receptor
\end{abstract}

\section{Acknowledgements}

We would like to thank the University of Zimbabwe Birth Cohort Study participants, study physicians and nurses for their contribution to this study. We are also indebted to Mr. Losco Gomo for assistance in obtaining demographics from the cohort database.

\section{Funding}

The Wellcome Trust contributed towards sample and demographic data collection. Financial support to travel to the National Health Laboratory Services, University of Witwatersrand, Johannesburg, South Africa was made possible by the International Federation of Clinical Chemistry (IFCC) through their Professional Scientific Exchange Program (PSEP). Test kits and materials for vitamin D analysis were facilitated by Professor Jaya George.

\section{Authors' contributions}

Conception of the study: RC, CM and KD. Performed the experiments: RC and TS. Statistical analysis: RC, KM and JAG. Contributed reagents and materials: TS and JAG. All authors made substantial revision this paper. All authors read and approved the final manuscript.

\section{Ethics approval and consent to participate}

All participants gave written informed consent and had consented to use of their archived specimens for cohort sub studies. The study protocol was approved by the Joint Research Ethics Committee (JREC) for the University of Zimbabwe College Health Sciences and the Parirenyatwa Group of Hospitals: JREC 13/16. Ethical approval was also obtained from the Medical Research Council of Zimbabwe (MRCZ), approval MRCZ /B/1117. Shipment of biospecimens from Harare to Johannesburg was approved by the Research Council of Zimbabwe (RCZ), research registration certificate 02871.

\section{Consent for publication}

Not applicable.

\section{Competing interests}

The authors declare that they have no competing interests.

\section{Publisher's Note}

Springer Nature remains neutral with regard to jurisdictional claims in published maps and institutional affiliations.

\section{Author details}

Department of Chemical Pathology, University of Zimbabwe, College of Health Sciences, P.O. Box A178, Avondale, Harare, Zimbabwe. ${ }^{2}$ Department of Immunology, University of Zimbabwe, College of Health Sciences, P.O. Box A178, Avondale, Harare, Zimbabwe. ${ }^{3}$ Department of Chemical Pathology, National Health Laboratory Service and University of the Witwatersrand, Parktown, Johannesburg, South Africa.

Received: 9 November 2017 Accepted: 22 March 2019

Published online: 28 June 2019

\section{References}

1. Erlandson KM, Gudza I, Fiorillo S, Ndemera B, Schooley RT, Gwanzura L, Borok M, Campbel TB. Relationship of vitamin D insufficiency to AIDSassociated Kaposi's sarcoma outcomes: retrospective analysis of a prospective clinical trial in Zimbabwe. Int J Infect Dis. 2014;24:6-10.

2. Reily L, Nausch N, Midzi N, Mduluza T, Mutapi F. Association between micronutrients (vitamin a, D, iron) and schistosome-specific cytokine responses in Zimbabweans exposed to Schistosoma haematobium. J Parasitol Res. 2012;2012:9.

3. Powis K, Lockman S, Smeaton L, Hughes MD, Fawzi W, Ogwu A, Moyo S, van Widenfelt E, von Oettingen J, Makhema J, Essex M. Vitamin d insufficiency in HIV-infected pregnant women receiving antiretroviral therapy is not associated with morbidity, mortality or growth impairment in their uninfected infants in Botswana. Pediatr Infect Dis J. 2014;33(11):1141.

4. Mehta S, Giovannucci E, Mugusi FM, Spiegelman D, Aboud S, Hertzmark E, Msamanga GI, Hunter D, Fawzi WW. Vitamin D status of HIV-infected women and its association with HIV disease progression, anemia, and mortality. PLoS One. 2010 Jan 19;5(1):e8770.

5. Adorini L. Intervention in autoimmunity: the potential of vitamin $D$ receptor agonists. Cell Immunol. 2005 Feb 28;233(2):115-24.

6. Schleithoff SS, Zittermann A, Tenderich G, Berthold HK, Stehle P, Koerfer R. Vitamin D supplementation improves cytokine profiles in patients with congestive heart failure: a double-blind, randomized, placebo-controlled trial. Am J Clin Nutr. 2006 Apr 1;83(4):754-9.

7. George JA. Vitamin D status and cardiometabolic risk factors in black African and Indian populations of South Africa (doctoral dissertation, Department of Chemical Pathology, Faculty of Health Sciences, University of the Witwatersrand).

8. George JA, Norris SA, van Deventer HE, Crowther NJ. The association of 25 hydroxyvitamin $D$ and parathyroid hormone with metabolic syndrome in two ethnic groups in South Africa. PLoS One. 2013 Apr 15;8(4):e61282.

9. Mohr SB. A brief history of vitamin D and cancer prevention. Ann Epidemiol. 2009 Feb 28;19(2):79-83.

10. Bodnar LM, Simhan HN, Powers RW, Frank MP, Cooperstein E, Roberts JM. High prevalence of vitamin D insufficiency in black and white pregnant women residing in the northern United States and their neonates. J Nutr. 2007 Feb 1;137(2):447-52.

11. Dawodu A, Akinbi H. Vitamin D nutrition in pregnancy: current opinion. Int J Women's Health. 2013 Jan 1;5:333-43.

12. Finkelstein JL, Mehta S, Duggan C. Maternal vitamin D status and child morbidity,anemia, and growth in human immunodeficiency virus-exposed children in Tanzania. Pediatr Infect Dis J. 2012;31(2).

13. Brannon PM, Picciano MF. Vitamin D in pregnancy and lactation in humans. Annu Rev Nutr. 2011 Aug 21;31:89-115.

14. Agarwal N, Faridi MM, Aggarwal A, Singh O. Vitamin D status of term exclusively breastfed infants and their mothers from India. Actapaediatrica. 2010;99(11):1671-4.

15. Alavena C, Delpierre C, Cuzin L, Rey D, Viget N, Bernard J, Guillot P, Duvivier C, Bilaud E, Raffi F. High frequency of vitamin D deficiency in HIV-infected patients: effects of HIV-related factors and antiretroviral drugs. J Antimicrob Chemother. 2012;67(9):2222-30.

16. Eckard AR, Leong T, Avery A, Castil o MD, Bonilla H, Storer N, Labbato D, Khaitan A, Tangpricha V, McComsey GA. Short communication: high prevalence of vitamin D deficiency in HIV-infected and HIV-uninfected pregnant women. AIDS Res Hum Retrovir. 2013;29(9):1224-8.

17. Bang UC, Shakar SA, Hitz MF, Jespersen MS, Andersen O, Nielsen SD, Jensen JE. Deficiency of 25-hydroxyvitamin D in male HIV-positive patients: a descriptive cross-sectional study. Scand J Infect Dis. 2010;42(4):306-10. 
18. Mansueto P, Seidita A, Vitale G, Gangemi S, laria C, Cascio A. Vitamin D deficiency in HIV infection: not only a bone disorder. Biomed Res Int. 2015 Apr 27;2015

19. Clemens TL, Henderson SL, Adams JS, Holick MF. Increased skin pigment reduces the capacity of skin to synthesise vitamin D3. Lancet. 1982 Jan 9; 319(8263):74-6.

20. Hagenau T, Vest R, Gissel TN, Poulsen CS, Erlandsen M, Mosekilde L, Vestergaard P. Global vitamin D levels in relation to age, gender, skin pigmentation and latitude: an ecologic meta-regression analysis. Osteoporos Int. 2009;20(1):133.

21. Saraf R, Morton SM, Camargo Jr CA, Grant CC. Global summary of maternal and newborn vitamin D status-a systematic review. Matern Child Nutr 2016; 12(4):647-668

22. Hilman LS, Slatopolsky E, Haddad JG. Perinatal vitamin D metabolism. IV. Maternal and cord serum 24, 25-dihydroxyvitamin D concentrations. J Clin Endocrinol Metabol. 1978;47(5):1073-7.

23. Kovacs CS. Maternal vitamin D deficiency: fetal and neonatal implications. InSeminars in fetal and neonatal medicine 2013 Jun 30 (Vol. 18, no. 3, pp. 129-135). WB Saunders.

24. Haug C, Müller F, Aukrust P, Frøland SS. Subnormal serum concentration of 1, 25-vitamin D in human immunodeficiency virus infection: correlation with degree of immune deficiency and survival. J Infect Dis. 1994 Apr 1; 169(4):889-93.

25. Toko EN, Sumba OP, Daud II, Ogolla S, Majiwa M, Krisher JT, Ouma C, Dent AE, Rochford R, Mehta S. Maternal vitamin D status and adverse birth outcomes in children from rural Western Kenya. Nutrients. 2016 Dec 7;8(12):794.

26. Saintonge $\mathrm{S}$, Bang $H$, Gerber LM. Implications of a new definition of vitamin D deficiency in a multiracial US adolescent population: the National Health and nutrition survey III. Pediatrics. 2009;123(3):797-803.

27. Hollis BW. Circulating 25-hydroxyvitamin D levels indicative of vitamin D sufficiency: implications for establishing a new effective dietary intake recommendation for vitamin D. JNutr. 2005;135:317-22.

28. Dawson-Hughes B, Heaney RP, Holick MF, Lips P, Meunier PJ, Vieth R. In: Burckhardt P, Dawson-Hughes B, Heaney R, editors. Vitamin D round table. Nutritional Aspects of Osteoporosis. Burlington, MA: Elsevier Science and Technology Books; 2004. p. 263-70.

29. Palacios C, Gonzalez L. Is vitamin D deficiency a major global public health problem? J Steroid Biochem Mol Biol. 2014;144:138-45.

30. Holmes VA, Barnes MS, Alexander MD, McFaul P, Wallace JM. Vitamin D deficiency and insufficiency in pregnant women: a longitudinal study. $\mathrm{Br}$ J Nutr. 2009;102(06):876-81.

31. Bowyer L, Catling-Paull C, Diamond T, Homer C, Davis G, Craig ME. Vitamin D, PTH and calcium levels in pregnant women and their neonates. Clin Endocrinol. 2009 Mar 1;70(3):372-7.

32. Jiang $L, X u J$, Pan S, Xie E, Hu Z, Shen H. High prevalence of hypovitaminosis $D$ among pregnant women in Southeast China. ActaPaediatrica. 2012;101(4):e192-4

33. Das V, Agarwal A, Bhatia V, Pandey A, Agarwal S, Saxena P, Sahu M. 0205 evaluation of Vit D status and need for supplementation in pregnant women of a rural area of North India. J Gynecol Obstet. 2009;107:S.

34. Hadden DR, McLaughlin C. Normal and abnormal maternal metabolism during pregnancy. InSeminars in fetal and neonatal medicine 2009 Apr 30 (Vol. 14, no. 2, pp. 66-71). WB Saunders.

35. Novakovic B, Sibson M, Ng HK, Manuelpillai U, Rakyan V, Down T, Beck S, Fournier T, Evain-Brion D, Dimitriadis E, Craig JM. Placenta-specific methylation of the vitamin d 24-hydroxylase gene implications for feedback autoregulation of active vitamin d levels at the fetomaternal interface. J Biol Chem. 2009;284(22):14838-48.

36. Gomme PT, Bertolini J. Therapeutic potential of vitamin D-binding protein. Trends Biotechnol. 2004 Jul 31;22(7):340-5.

37. ME BDM, Bravenboer B, Koopmans PP, Van Der Ven AJ. Vitamin D deficiency among HIV type 1-infected individuals in the Netherlands: effects of antiretroviral therapy. AIDS Res Hum Retrovir. 2008;24(11):1375-82.

38. Suderman M, Stene LC, Bohlin J, Page CM, Holvik K, Parr CL, Magnus MC, Håberg SE, Joubert BR, Wu MC, London SJ. 25-Hydroxyvitamin D in pregnancy and genome wide cord blood DNA methylation in two pregnancy cohorts (MoBa and ALSPAC). J Steroid Biochem Mol Biol. 2016;159:102-9.

39. Tai SS, Bedner M, Phinney KW. Development of a candidate reference measurement procedure for the determination of 25-hydroxyvitamin D3 and 25-hydroxyvitamin D2 in human serum using isotope-dilution liquid chromatography- tandem mass spectrometry. Anal Chem. 2010;82(5):1942-8.
40. Stepman HC, Vanderroost A, Van Uytfanghe K, Thienpont LM. Candidate reference measurement procedures for serum 25-hydroxyvitamin D3 and 25-hydroxyvitamin D2 by using isotope-dilution liquid chromatographytandem mass spectrometry. Clin Chem. 2011;57(3):441-8.

41. Bakhtiyarova S, Lesnyak O, Kyznesova N, Blankenstein MA, Lips P. Vitamin D status among patients with hip fracture and elderly control subjects in Yekaterinburg, Russia. Osteoporos Int. 2006 Mar 1;17(3):441-6.

42. Holick MF. High prevalence of vitamin D inadequacy and implications for health. InMayo clinic proceedings 2006 mar 31 (Vol. 81, no. 3, pp. 353-373). Elsevier.

43. Webb AR, Kline L, Holick MF. Influence of season and latitude on the cutaneous synthesis of vitamin D3: exposure to winter sunlight in Boston and Edmonton will not promote vitamin D3 synthesis in human skin. J Clin Endocrinol Metabol. 1988;67(2):373-8.

44. Ramayo E, Gonzalez-Moreno MP, Macias J, Cruz-Ruiz M, Mira JA, Vilar-Rueda AM, Garcia-Garcia JA, Gomez-Mateos JM, Lozano F, Pineda JA. Relationship between osteopenia, free testosterone, and vitamin D metabolite levels in HIV-infected patients with and without highly active antiretroviral therapy. AIDS Research \& Human Retroviruses. 2005;21(11):915-21.

45. Zakeri H. Vitamin D deficiency prevalence in summer compared to winter in a city with high humidity and a sultry climate. Women. 2011;94:90-6.

Ready to submit your research? Choose BMC and benefit from

- fast, convenient online submission

- thorough peer review by experienced researchers in your field

- rapid publication on acceptance

- support for research data, including large and complex data types

- gold Open Access which fosters wider collaboration and increased citations

- maximum visibility for your research: over $100 \mathrm{M}$ website views per year

At $\mathrm{BMC}$, research is always in progress.

Learn more biomedcentral.com/submissions 